\title{
Investigation of Hyperglycaemia and Associated Factors among Pregnant Women Attending Antenatal at Mulago Hospital, Directorate of Obstetrics and Gynaecology, Kawempe.
}

\author{
Journal of Obstetrics and Gynaecology@SJHR-Africa. \\ Derek Muhoozia,1,2 \\ a Faculty of Health Sciences, Uganda Martyrs University, \\ Kampala, Uganda
}

\begin{abstract}
Introduction: This study aimed at establishing the prevalence and factors associated with hyperglycemia in pregnancy among women attending treatment at antenatal care at the Directorate of obstetrics and gynaecology at Kawempe under the following objectives; to determine the prevalence of hyperglycemia in pregnancy, to establish the factors associated with hyperglycemia in pregnancy. Methods: The study was cross-sectional and experimental in design that recruited 333 participants from age 18 years and above. The consented participants filled a questionnaire that was taking history and demographics. A blood sample was taken for blood glucose testing and a urine sample was also collected. Data was entered in Epidata 3.1 and exported to SPSS 17.0 for analysis. Descriptive statistics and multivariate analysis was used to determine prevalence and factors associated with hyperglycemia in pregnancy

Results: Laboratory tests revealed that the prevalence of hyperglycemia was $25.3 \%$ (84). The following factors were significantly associated with hyperglycemia in pregnancy; age37 years and above ( $p$-value 0.013* OR 2.34), and high Body Mass Index (BMI) (p-value 0.002* OR 3.744). Gravidity of 3-4 times ( $p$-value $0.003^{*}$ OR3.782), $>=5$ times ( $p$-value $<0.001 *$ and OR3.099), parity of $>=5$ children ( $p$-value $0.003 * O R 3.642$ ), first degree hyperglycaemia (P-value $<0.031 * O R 5.152$ ), high blood pressure during this pregnancy $\left(0.012{ }^{*} \mathrm{OR} 3.622\right)$ and high blood pressure while not pregnant ( $p$-value $0.012{ }^{*} \mathrm{OR}$ 1.274).

Conclusion and recommendations:

Gestational hyperglycemia is common among women attending care at the directorate of Obstetrics and Gynecology at Kawempe. the commonest factors associated with hyperglycemia in pregnancy are high Body mass index, history of hypertension, history of hyperglycemia, high parity high gravidity, there is no relationship between hyperglycemia and sexually transmitted diseases like HIV, and syphilis.
\end{abstract}

\footnotetext{
${ }^{1}$ Corresponding author.

2E-mail: derekmuhoozi95@gmail.com
} 


\section{Background}

During pregnancy, endocrine and metabolic changes occur that may predispose some women to hyperglycemia, especially those whose pancreatic function cannot overcome these diabetogenic changes while pregnant (Butte et al., 2016). According to Crowthel et al., (2012), hyperglycemia during pregnancy puts women at a higher risk of adverse outcomes like fetal macrosomia, obstructed labor, birth injuries, and maternal and prenatal mortality (Dodd et al., 2014). Coupled with the above, is the long-term health impact of increased risk of developing type 2 diabetes. Cumulative risks of incident diabetes in gestational hyperglycaemic patients ranging from $2.6 \%$ to over $70 \%$ within $5-10$ years of delivery have been reported (Chodick, et al.,2010). Moreover, their offspring have a higher prevalence of childhood obesity and an overweight and higher risk of developing type 2 DM later in life (Dabelea, 2013).

Hyperglycaemia is one of the most common medical disorders seen in women encountered in pregnancy. The International Diabetes Federation (IDF) estimates that one in six live births (16.8\%) is to women with some form of hyperglycemia in pregnancy. Of them, $84 \%$ are gestational diabetes mellitus (GDM), while $16 \%$ may be due to diabetes in pregnancy (either pre-existing diabetes-type 1 or type 2-which antedates pregnancy or is first identified during testing in the index pregnancy (IDF, 2013). The gestational hyperglycemia prevalence corresponds with the prevalence of impaired glucose tolerance (IGT) and type 2 diabetes mellitus (T2DM) in any given population. Unfortunately, the age of onset of pre-diabetes and diabetes is declining, whereas childbearing age is increasing. Moreover, overweight and obesity are increasing in women of reproductive age; thus, more women who are entering pregnancy have risk factors that make them vulnerable to hyperglycemia during pregnancy. GDM is associated with a higher incidence of cesarean deliveries, shoulder dystocia, birth trauma, hypertensive disorders of pregnancy (including pre-eclampsia), and these women are at higher risk for development of T2DM (Moshe et al., 2015).

According to Hod et al., (2015), the perinatal and neonatal morbidities also increase; the latter include macrosomia, neonatal hypoglycemia, birth injury, polycythemia, and hyperbilirubinemia. Moreover, offspring in utero, if exposed to maternal hyperglycemia may remain at higher risks for childhood obesity and diabetes later in life. By early detection, aggressive management and adequate education protects both the mother and offspring of this diabetic mother (WHO, 2013)

The prevalence of gestational hyperglycemia has been reported to vary between $1 \%-28 \%$ in different regions of the world. The International Diabetes Federation (IDF) estimates that one in six live births (16.8\%) are to women with some form of hyperglycemia in pregnancy; $16 \%$ of these may be due to Diabetes in pregnancy (Butte et al., 2016). A south Indian study showed the prevalence to be $13.9 \%$. It was $17.8 \%$ in Urban, $13.8 \%$ in semi-urban, and $9.9 \%$ in rural Indian women. Among the women with GDM, $12.4 \%$ were detected within 16 weeks of pregnancy, 23\% between 17 and 23 weeks, and the remaining $64.6 \%$ at more than 24 weeks of pregnancy. However, in Uganda, there is no country data available about factors associated with gestational hyperglycemia (Nakabuye et al., 2017). However, the estimate modeled using data from other countries and specific country characteristics showed the prevalence of raised fasting blood glucose among females aged $\geq 25$ years as $6.5 \%$; the prevalence of raised blood pressure among women aged $\geq 25$ years as $39.6 \%$ and women aged $\geq 20$ years who are obese are about $4.9 \%$ (WHO, 2017). This is predictive of gestational hyperglycemia and its related events (Hedderson et al.,2012). Gestational hyperglycemia has far-reaching effects on the mother and the baby with the likelihood of getting obstetric complications and growth disorders.

\section{Study design}

\section{Methodology:}

This was a cross-sectional study design

\section{Study site/area}

This study was conducted at Mulago National Referral Hospital, Kawempe, in the directorate of obstetrics and gynecology. The hospital has a bed capacity of over 1500. It is a tertiary care facility and a teaching hospital. It serves the suburbs around Kampala and referrals from all over the country as well as the Great Lakes region and South Sudan. 


\section{Study population}

The study was carried out on pregnant women attending care at the directorate of obstetrics and gynecology at Kawempe.

\section{Sample size determination}

Sample size had been estimated using the Kish and Leslie formula of 1965 for descriptive studies sample size calculation.

Where;

Is the number of respondents required for the study

Is the value corresponding to a $95 \%$ confidence interval or risk level (1.96)

$p=31.9 \%$, the reported prevalence of pregnant women with hyperglycemia

$q: 1-p$

$d=$ the study will accommodate an error of $5 \%$.

$\mathrm{n}=333$ participants

\section{Sampling method}

The participants were selected randomly. All pregnant women attending care were assigned random numbers. Anyone who obtained an even number was selected until the required number of 333 was reached.

\section{Inclusion criteria}

The main inclusion criteria were the state of being pregnant, above 18 years of age, and attending care from the Directorate of obstetrics and gynecology during the study period. Also, the participant should have made an informed consent to participate in the study.

\section{Exclusion criteria}

Non-pregnant women and those who declined to consent were excluded from the study.

\section{Study instrument}

A pretested and standardized questionnaire was used to collect demographic data and all data necessary to the study associated factors.

\section{Variables}

The study's independent variables included socio-demographic characteristics like age, sex, smoking, alcohol intake, occupation, BMI. The dependent variables were random blood glucose and urine glucose levels.

\section{Procedure}

After the consent process, the ladies were requested to fill a questionnaire with the help of the study assistants. The consented participants were sent for a urine sample and afterward, random blood glucose was determined using a glucometer.

\section{Quality control}

The questionnaire was pretested and translated into the most frequently used local language at the facility (that is, Luganda). The questionnaires and data sheets were cross-checked for completeness daily. Data were double entered into the data software (EPI-DATA 3.1) to minimize errors.

\section{Data management and analysis}

Questionnaires were cross-checked after each day of data collection to make certain the correctness and completeness of the collected data. Data were then entered into Epidata 3.1, cleaned, and also double cross-checked to minimize errors. Data were stored in a computer hard drive and a backup made on a flash drive. After the data entry process and checking, it was then exported to STATA 13.0 for analysis. Statistical tests of significance were performed including Pearson Chi-square and regression analysis to identify variable relationships. Results were presented in tables and graphs.

\section{Ethical consideration}

An introductory letter to the head of the Directorate of Gynaecology and Obstetrics was obtained from the department. Informed consent was sought from the participants before enrolment in the study after a thorough explanation of the nature of the study risk and benefits. Confidentiality was maintained by coding data with numbers and not patient names. Study files were kept under lock and key.

\section{Dissemination of results}


Table 1. Shows the socio-demographic characteristics of the respondents

\begin{tabular}{llll}
\hline Variable & Items & Frequency & Percent \\
Age & 18-27 years & 189 & 56.7 \\
& 28-37years & 80 & 24 \\
& 37 and above & 64 & 19 \\
Education & Not educated & 75 & 22.5 \\
level & Primary level & 125 & 37.5 \\
& Secondary Level & 83 & 25 \\
& Tertiary Level & 33 & 10.0 \\
\multirow{4}{*}{ Occupation } & Student & 108 & 32.5 \\
& Peasant Farmer & 16 & 5.0 \\
& Formal employment & 33 & 27.5 \\
& House wife & 66 & 10.0 \\
\hline
\end{tabular}

Table 2. Shows the Obstetric H istory

\begin{tabular}{lll}
\hline Number of pregnancies carried by the participant & Frequency & Percentage \\
Once & 23 & 7 \\
2-4 times & 124 & 36 \\
$\geq 5$ times & 194 & 57 \\
Current living children & & \\
1 child & 30 & 11 \\
2-4 children & 111 & 44 \\
$\geq 5$ children & 164 & 45 \\
No of ANC before delivery & & \\
$1-3$ times & 213 & 64.0 \\
$4-6$ times & 120 & 36.0 \\
\hline
\end{tabular}

Four copies of the study report were printed and distributed to Mulago Hospital, Directorate of Obstetrics and gynecology, Research and ethics committee, examination purposes, and the fourth copy will be for the supervisor.

\section{Results:}

Socio-demographic characteristics of the respondents

$$
\mathrm{N}=333
$$

Majority of the respondents $56.7 \%$ (189) were between $18-27$ years of age. This was followed by $24 \%$ (80) of those between 28 - 37 years of age. Only $18 \%$ (64) were either 37 years of age, or were above this age. Majority of the respondents $37.5 \%$ (125) had attained primary level followed by $25 \%$ (83) secondary level. At least $22.5 \%$ (75) had not attained any level of formal education. Only $10 \%$ (33) had attained tertiary level education.

The study found out that majority respondents 32.5\% (108) were peasant farmers by occupation, $27.5 \%$ (92) were students, $20 \%$ (66) were housewives, $10 \%$ (33) were in formal employment and only 5\%(16) were business women.

\section{Obstetric $\mathrm{H}$ istory}

$\mathrm{N}=333$

Majority of the respondents $57 \%$ (194) had gravidity of $\geq 5$ times, followed by $36 \%$ (124) 2-4 times, and $7 \%$ (23) of first gravida. Majority of the respondents at $45 \%(164)$ had parity of $\geq 5,44 \%$ (111) $2-4$ and $11 \%(30)$ had a single child. 
Table 3. Shows the demographic characteristics and association with hyperglycaemia in pregnancy

\begin{tabular}{|c|c|c|c|}
\hline Variables & Descriptive & OR (95\% confidence Interval ) & P-value \\
\hline \multicolumn{4}{|l|}{ Age } \\
\hline $18-27$ years & $189(56.7)$ & $2.10(0.6-1.8)$ & 0.813 \\
\hline 28-37years & $80(24)$ & $3.13(2.0-4.0)$ & 0.532 \\
\hline 37 and above & $64(19)$ & $2.34(0.3-3.0)$ & $0.013^{*}$ \\
\hline \multicolumn{4}{|l|}{ Occupation } \\
\hline Peasant Farmer & $108(32.5)$ & $1.274(0.6-2.8)$ & 0.553 \\
\hline Business person & $16(5.0)$ & $1.425(0.8-2.7)$ & 0.278 \\
\hline Student & $92(27.5)$ & $1.010(0.6-1.8)$ & 0.973 \\
\hline Formal employment & $33(10.0)$ & $1.337(0.6-3.2)$ & 0.507 \\
\hline House wife & $66(20.0)$ & $0.749(0.3-1.8)$ & 0.507 \\
\hline \multicolumn{4}{|l|}{ Level of education } \\
\hline Not educated & $75(22.5)$ & $1.671(0.6-4.5)$ & 0.314 \\
\hline Primary level & $83(25.0)$ & $0.938(0.3-2.5)$ & 0.899 \\
\hline Secondary Level & $125(37.5)$ & $1.337(0.6-3.2)$ & 0.507 \\
\hline Tertiary Level & $33(10.0)$ & $0.749(0.3-1.8)$ & 0.507 \\
\hline \multicolumn{4}{|l|}{ BMI } \\
\hline High & $80(24.0)$ & $3.744(1.6-8.7)$ & $0.002 *$ \\
\hline Low & $75(22.5)$ & $1.274(0.6-2.8)$ & 0.853 \\
\hline Normal & $178(53.4)$ & $1.425(0.8-2.7)$ & 0.378 \\
\hline
\end{tabular}

\section{Prevalence of hyperglycaemia in Pregnancy}

\section{$\mathrm{N}=333$}

The study found out that majority of the respondents $60.6 \%$ (202) had not had any history of hyperglycaemia. However, $22.3 \%$ (74) had had a history of hyperglycaemia, while those who did not know their earlier status were $17.1 \%$ (57) without the a history of hyperglycaemia.

\section{Factors associated with Hyperglycaemia in pregnancy}

\section{Demographic characteristics}

Demographic characteristics and association with hyperglycaemia in pregnancy

The study found out the following demographic features as significantly associated with hyperglycaemia in pregnancy; those who were 37 years or older ( $p$-value 0.013* OR 2.34), and high Body Mass index (BMI) (p-value 0.002* OR 3.744).

\section{Obstetric history and its association with hyperglycaemia}

Obstetric history associated with hyperglycaemia in pregnancy

The study found out the following obstetric history as significantly associated with hyperglycaemia in

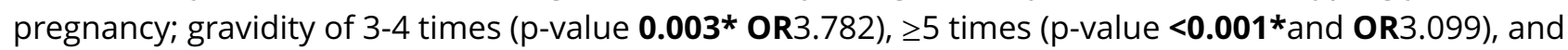
parity of $\geq 5$ (p-value $\mathbf{0 . 0 0 3 * O R} 3.642$ ).

\section{History of Hyperglycaemia and hypertension}

History of hypertension and hyperglycaemia and its relationship with hyperglycaemia in pregnancy

The study found out the following history of hyperglycaemia and hypertension as significantly associated with hyperglycaemia in pregnancy; first degree hyperglycaemia (P-value <0.031*OR 5.152), high blood pressure during this pregnancy $(\mathbf{0 . 0 1 2 *} \mathrm{OR} 3.622)$ and high blood pressure while not pregnant ( $p$-value 0.012*OR 1.274)

\section{STIs and Hyperglycaemia in pregnancy}

The study found no significant relationship between hyperglycaemia in pregnancy and STIs such as HIV and Syphilis.

\section{DISCUSSION}


Table 4. Shows Obstetric history associated with hyperglycaemia in pregnancy

\begin{tabular}{|c|c|c|c|}
\hline \multicolumn{4}{|l|}{ Gravidity } \\
\hline Once & $23(7)$ & $1.274(0.6-2.8)$ & 0.553 \\
\hline 2-4 times & $124(36)$ & $3.782(1.6-9.1)$ & $0.003 *$ \\
\hline$>=5$ times & $194(57)$ & $3.099(1.7-5.5)$ & $<0.001 *$ \\
\hline \multicolumn{4}{|l|}{ Parity } \\
\hline 1 child & $30(11)$ & $1.471(0.6-4.5)$ & 0.314 \\
\hline 2-4 children & $111(44)$ & $0.738(0.3-2.5)$ & 0.899 \\
\hline$>=5$ children & $164(45)$ & $3.642(1.6-8.7)$ & $0.003^{*}$ \\
\hline \multicolumn{4}{|c|}{ Gestation age at first ANC } \\
\hline $18-27$ years & $189(56.7)$ & $1.310(0.6-3.0)$ & 0.522 \\
\hline 28-37years & $80(24)$ & $0.885(0.4-2.0)$ & 0.773 \\
\hline 37 and above & $64(19)$ & $5.152(2.5-10.8)$ & $<0.001 *$ \\
\hline \multicolumn{4}{|c|}{ Number of ANC visits before delivery } \\
\hline $1-3$ times & $213(64.0)$ & $1.374(0.6-2.8)$ & 0.653 \\
\hline 4-6 times & $120(36.0)$ & $1.425(0.8-2.7)$ & 0.578 \\
\hline
\end{tabular}

Table 5. Shows History of hypertension and hyperglycaemia and its relationship with hyperglycaemia in pregnancy

\begin{tabular}{llll}
\hline First degree relative with high blood glucose levels & & & \\
Yes & $49(14.7)$ & $5.152(2.5-10.8)$ & $<0.01^{*}$ \\
No & $187(56.1)$ & $1.274(0.6-2.8)$ & 0.523 \\
Do not know & $97(29.1)$ & $1.425(0.8-2.7)$ & 0.478 \\
History of hypertension & & & \\
High blood pressure during pregnancy & & & \\
Yes & $134(40.2)$ & $1.274(0.6-2.8)$ & 0.724 \\
No & 199 & $1.010(0.6-1.8)$ & 0.579 \\
High blood pressure during this pregnancy & & & \\
Yes & $97(29.1)$ & $3.622(1.6-8.7)$ & $\mathbf{0 . 0 1 2 ^ { * }}$ \\
No & $236(70.8)$ & $1.254(0.6-2.8)$ & 0.824 \\
High blood pressure while not pregnant & $38(16)$ & & \\
Yes & 47 & $1.274(0.6-2.8)$ & $\mathbf{0 . 0 1 2 ^ { * }}$ \\
No & 286 & $1.010(0.6-1.8)$ & 0.579 \\
\hline
\end{tabular}

Table 6. Relationship between hyperglycaemia in pregnancy and STIS

\begin{tabular}{llll}
\hline Presence of STIS & & & \\
HIV & $21(6.3)$ & $8.590(4.3-17.0)$ & 0.701 \\
Syphillis & $27(8.1)$ & $1.103(0.5-1.7)$ & 0.123 \\
\hline
\end{tabular}


Blood samples were taken from the pregnant women and laboratory tests for blood glucose were done and a urine glucose test was also done. Laboratory tests revealed that $25.3 \%$ (84) had hyperglycemia, $66.5 \%$ (221) had normal glucose levels in the blood and $8.2 \%$ (27) had low blood glucose levels. Hyperglycaemia was found to be at $25.3 \%$ and this is higher than the global prevalence that was estimated at $16.9 \%$ by the World Health Organisation in 2013. as the highest prevalence was $25.0 \%$ in South-East Asia and the lowest $10.4 \%$ in North America and the Caribbean Region in 2013. Low- and middle-income countries contribute $90 \%$ of the cases in the world (WHO, 2013). Therefore, several women carrying pregnancies with such high hyperglycemia pose a risk to the babies they carry. However, what is more, disturbing is the fact that the majority of the women do not attend ANC to have a blood sugar test done. This study for example found out that fewer women $36.0 \%$ (120) attend more than 4 times at ANC. This low ANC attendance is cited in complicating several obstetric adverse events like hypertension, eclampsia leading to low birth weights, complicated deliveries, and sometimes maternal deaths. According to the International Diabetes Federation (IDF), $16.8 \%$ of pregnant women have some form of hyperglycemia in pregnancy (Butte et al.,2016). This is lower than $25.3 \%$ as observed in this study. Therefore, hyperglycemia in pregnancy is a common phenomenon in Uganda and it needs urgent interventions. However, its link to maternal death has not been established.

\section{Gestational hyperglycemia associated factors}

A multivariate analysis was done to determine what could be the factors that associate with the observed hyperglycemia of $25.3 \%$ among pregnant women. The study found maternal age of 37 years and above ( $p$-value 0.013* OR 2.34), and high Body Mass Index (BMI) ( $p$-value 0.002* OR 3.744) as being significantly associated with hyperglycemia. These findings agree with the study by Seshiah et al (2015) where gestational diabetes mellitus had the highest prevalence in women with a BMI greater than 25 , with $28.4 \%$ in the urban area, $23.8 \%$ in the semi-urban area, and $16.1 \%$ in the rural area. Also, Seshiah et al (2015) found out that a family history of diabetes was associated with the prevalence of GDM in India. Based on multiple logistic regression analysis taking all 3 areas into consideration, family history and BMI greater than 25 were found to have a significant independent association $(P<0.001)$ with GDM.

Seshiah et al (2015) findings are consistent with the findings in this study where it was found out that a history of hyperglycemia and hypertension is significantly associated with hyperglycemia in pregnancy; first-

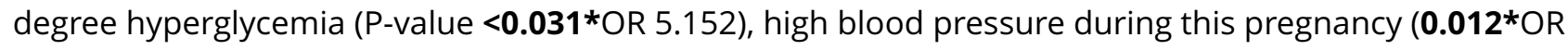
3.622) and high blood pressure while not pregnant ( $p$-value $\mathbf{0 . 0 1 2}{ }^{*} \mathrm{OR} 1.274$ ). Therefore, those with a history of factors that predispose to hyperglycemia in pregnancy may have the condition worsen if not handled well during the pregnancy. For example, management of hypertension in pregnancy should always be done for those mothers with hypertension as this can lead to hyperglycemia.

Also, this study found out the following obstetric history as significantly associated with hyperglycemia

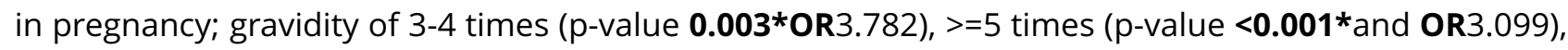
parity of $>=5$ children ( $p$-value $\mathbf{0 . 0 0 3 *}$ OR 3.642). According to Berger et al (2012), the following can lead to gestational hyperglycemia; obesity, older age, multi-parity, excessive weight gain during pregnancy, short stature, polycystic ovarian syndrome (PCOS), family history of diabetes mellitus in first degree relatives, a history of abortion, fetal loss, macrosomia, preeclampsia, and multifoetal pregnancy. However, more studies need to be done to qualify gravidity and parity as key associated factors to caution women who wish to have as many babies as possible. The study found no significant relationship between hyperglycemia in pregnancy and STIs like HIV/AIDS and syphilis.

\section{Conclusions}

Gestational hyperglycemia is common among women attending care at the directorate of Obstetrics and Gynaecology at Kawempe. The commonest factors associated with hyperglycemia in pregnancy were high body mass index, history of hypertension, history of hyperglycemia, high parity, and high gravidity. There is no relationship between hyperglycemia and sexually transmitted diseases like HIV/AIDS and syphilis. There was also a significant number of women who had hypoglycemia.

\section{Recommendations}


Routine screening for urine and blood glucose levels should be done for every pregnant woman who visits the ANC. New policy guidelines for maternal care should include researched guidelines on hyperglycemia in pregnancy.

\section{Areas for further investigation.}

More studies should be done to find out how parity and gravidity contribute to hyperglycemia in pregnancy. Also, research needs to be done on the life of babies born to mothers with hyperglycemia to further document the effects of the condition.

Fasting blood samples should be used in the coming studies to accurately diagnose the condition.

\section{Acknowledgement.}

I would like to begin by expressing my appreciation first to my Supervisor, Mr Muwonge Kizito and Dr .Kasibante Samuel for the support given to me during my research .

For my qualitative and quantitative research teams, thank you for enduring the hot sun and long working hours during data collection. Special thanks go to the administration of Mulago National referral hospital, the Directorate of obstetrics and gynaecology at Kawempe, first for giving me this invaluable opportunity to participate in this excellent and informative study.

\section{References}

[1] E Odar, J Wandabwa, and P Kiondo. Maternal and fetal outcome of gestational diabetes mellitus in Mulago Hospital. Uganda. Afr Health Sci, 4(1):9-14, 2014.

[2] Veerasamy Seshiah, Vijayam Balaji, Madhuri S. Balaji, Arunachalam Paneerselvam, and Anil Kapur. Pregnancy and diabetes scenario around the world: India. International Journal of Gynecology \& Obstetrics, 104(Supplement):S35-S38, 2009.

[3] Diagnostic criteria and classification of hyperglycaemia first detected in pregnancy. Geneva: World Health Organization. WHO, 2013.

[4] M M Hedderson, M A Williams, V L Holt, N S Weiss, and A Ferrara. Body mass index and weight gain prior to pregnancy and risk of gestational diabetes mellitus. Am J Obstet Gynecol, 198(4):409-410, 2012.

[5] H Berger, J Crane, D Farine, A Armson, S De La Ronde, Keenan-Lindsay, and L. Screening for gestational diabetes mellitus. J Obstet Gynaecol Can, 24:894-912, 2012.

[6] IDF Atlas Sixth Edition Brussels Belgium: International Diabetes Federation. International Diabetes Federation, 2013.

[7] N F Butte. Carbohydrate and lipid metabolism in pregnancy: normal compared with gestational diabetes mellitus. Am J Clin Nutr, 71(5):1256-1261, 2016.

[8] World Health Organization. World health statistics, 2018.

[9] M Hod, A Kapur, D A Sacks, E Hadar, M Agarwal, G C Di Renzo, and H Divakar. The International Federation of Gynecology and Obstetrics (FIGO) Initiative on gestational diabetes mellitus: A pragmatic guide for diagnosis, management, and care. International Journal of Gynecology and Obstetrics, 131:30007-30009, 2015.

[10] E. Cosson, A. Benbara, I. Pharisien, M. T. Nguyen, A. Revaux, B. Lormeau, D. Sandre-Banon, N. Assad, C. Pillegand, P. Valensi, and L. Carbillon. Diagnostic and Prognostic Performances Over 9 Years of a Selective Screening Strategy for Gestational Diabetes Mellitus in a Cohort of 18,775 Subjects. Diabetes Care, 36(3):598-603, 2013.

[11] D Dabelea. The predisposition to obesity and diabetes in offspring of diabetic mothers. Diabetes Care, 30:169-174, 2013. 
[12] C G Solomon, W C Willett, V J Carey, J Rich-Edwards, D J Hunter, and G A Colditz. A prospective study of pregravid determinants of gestational diabetes mellitus. JAMA, 278(13):1078-1083, 1997.

[13] Betty Nakabuye, Silver Bahendeka, and Romano Byaruhanga. Prevalence of hyperglycaemia first detected during pregnancy and subsequent obstetric outcomes at St. Francis Hospital Nsambya. BMC Research Notes, 10(1):174-174, 2017.

[14] J M Dodd, C A Crowther, G Antoniou, P Baghurst, and J S Robinson. Screening for gestational diabetes: the effect of varying blood glucose definitions in the prediction of adverse maternal and infant health outcomes. Aust NZJ Obstet Gynaecol, 47(4):307-312, 2014.

[15] Moshe Hod, Anil Kapur, David A Sacks, Eran Hadar, Mukesh Agarwal, Gian Carlo Di Renzo, Luis Cabero Roura, Harold David Mcintyre, Jessica L Morris, and Hema Divakar. The International Federation of Gynecology and Obstetrics (FIGO) Initiative on gestational diabetes mellitus: A pragmatic guide for diagnosis, management, and care. International Journal of Gynecology and Obstetrics, 131(3):173-211, 2015.

[16] G. Chodick, U. Elchalal, T. Sella, A. D. Heymann, A. Porath, E. Kokia, and V. Shalev. The risk of overt diabetes mellitus among women with gestational diabetes: a population-based study. Diabetic Medicine, 27(7):779-785, 2010.

[17] N Freinkel and Banting. Of pregnancy and progeny. Diabetes, 29:1023-1058, 1980.

[18] L. Guariguata, U. Linnenkamp, J. Beagley, D. R. Whiting, and N. H. Cho. Global estimates of the prevalence of hyperglycaemia in pregnancy. Diabetes Research and Clinical Practice, 103(2):176-185, 2014.

[19] Crowther. The IDEAL study: investigation ofdietary advice and lifestyle for women with borderline gestationaldiabetes: a randomised controlled trial - study protocol. BMC Pregnancyand, 12:106-106, 2012. 